\title{
Odour emissions from tunnel-ventilated broiler sheds: case study of nine Queensland farms
}

\author{
Mark Dunlop ${ }^{\mathrm{A}, \mathrm{B}}$, Erin Gallagher ${ }^{\mathrm{A}}$ and Jae Ho Sohn ${ }^{\mathrm{A}}$ \\ A State of Queensland, Department of Employment, Economic Development and Innovation, \\ Agri-Science Queensland, PO Box 102, Toowoomba, Qld 4350, Australia. \\ ${ }^{\mathrm{B}}$ Corresponding author. Email: mark.dunlop@deedi.qld.gov.au
}

\begin{abstract}
Odour emission rates were measured from nine tunnel-ventilated broiler farms in south-eastern Queensland, Australia. At one farm, odour emission rates were measured over two sequential batches approximately weekly, while at the remaining farms, odour emission rates were measured just before the first pickup (around Day 35 of the batch) when bird liveweight was greatest and peak odour emission rates were expected. Odour samples were analysed using dynamic olfactometry (to AS/NZS 4323.3:2001), and an artificial olfaction system was used to continuously monitor odour emission rates at one farm. Odour emission rates ranged from 330 to $2960 \mathrm{ou} / \mathrm{s}$ per $1000 \mathrm{birds}$ and from 0.19 to $2.12 \mathrm{ou} / \mathrm{s} . \mathrm{kg}$, with a significant amount of variability observed throughout the batch and throughout each sampling day. While the wide range in odour emission rates was primarily due to changes in bird liveweight and ventilation requirements, other factors were also involved. The artificial olfaction system proved useful for quantifying the range and variability of odour emission rates, especially when olfactometry analysis was impractical.
\end{abstract}

Additional keywords: artificial olfaction system, electronic nose, emission rate, olfactometry.

\section{Introduction}

Odour from meat chicken (broiler) farms is a major environmental issue affecting the sustainable development of the chicken meat industry. Odours are a normal part of broiler production. The potential for odour nuisance is increasing due to more concentrated broiler farming, increasing population densities near broiler farms and greater air-quality requirements by the community. The setting-up of new broiler farms, or the expansion of existing farms, requires careful consideration and planning to ensure compatibility with adjacent land uses (EPA Qld Government 2004).

Broilers are commercially raised in specially designed sheds, with the majority of broiler sheds in south-eastern Queensland being tunnel ventilated. These sheds are long and narrow (typically 100-150 m long and 12-16 m wide) and have highcapacity axial fans mounted on one end of the shed that are automatically operated using a sophisticated control system. The primary purpose of the ventilation system is to remove heat and moist air from the shed, but the exhaust air will also contain odour. The floor of a broiler shed is covered with friable, absorbent bedding material, which is usually either fresh wood shavings or litter (mixture of wood shavings and manure from the previous batch of chickens). The production cycle for broilers typically lasts 56 days, and there may be 7-14 days between batches to allow shed cleaning, routine maintenance and distribution of bedding in preparation for the next batch of day-old chicks.

Odour is formed by combinations of hundreds of odorants, which are commonly classified as volatile organic compounds
(VOC) (O'Neill and Phillips 1992; Schiffman et al. 2001; Lacey et al. 2004; Cai et al. 2006). The concentration of odour is determined using dilution olfactometry, which involves presenting a series of diluted odorous air samples to a panel of trained human assessors using a standardised process. In Australia, odour concentration is assessed according to the Australian/New Zealand Standard AS/NZS 4323.3:2001 (Standards Australia/Standards New Zealand 2001).

While broiler-shed odour is primarily produced from the microbial decomposition of faeces in the litter (Jiang and Sands 2000; Hobbs et al. 2004), some odour may also be emitted from the birds themselves (Lacey et al. 2004). Odorous molecules are released from the litter and the birds into the shed ventilation air and exhausted from the shed through the fans. Once exhausted from the shed, the odour plume is subjected to dispersion, and is diluted as it travels downwind. When planning for a new or enlarged production facility, odour dispersion modelling is commonly used to estimate the likelihood of odour nuisance. It is dependent on accurate odour emission rate values. There is therefore a requirement for reliable odour emission rate data.

Odour emission rates from broiler sheds have been reported in the literature; Robertson et al. (2002) reported odour emission rates of 590-970 ou/s per 1000 birds, Hayes et al. (2006) reported odour emission rates of $50-1220 \mathrm{ou} / \mathrm{s}$ per 1000 birds and 0.18-0.73 ou/s.kg and Pollock and Anderson (2004), who reviewed odour emission rates measured at Australian broiler farms, reported odour emission rates of $66-2300 \mathrm{ou} / \mathrm{s}$ per 1000 
birds. These reported odour emission rate values demonstrate the wide range of odour emission rates that are emitted from broiler sheds.

The generation and emission of broiler-shed odour is influenced by several factors, primarily those that will affect microbial activity, diffusion and transport from the shed. These factors include litter moisture content, $\mathrm{pH}$, temperature, bird activity, litter properties, weather conditions, ventilation rate, air speed, manure quantity and diet (McGahan et al. 2002; Robertson et al. 2002; Carey et al. 2004; Hudson and Ayoko 2009; Hudson et al. 2009). It is unlikely these factors affect odour emission rates in isolation from each other, which introduces significant challenges when developing strategies to reduce odour emissions.

The net effect of the broiler production cycle, shed management and the aforementioned factors that determine odour emission rates, is that odour emission rates will vary throughout the batch cycle, diurnally and between farms (Pollock and Anderson 2004; Hayes et al. 2006). Anecdotal reports suggest that odour emissions peak just before the first pickup in weeks 5-6 of the production cycle, and then reduce as birds are removed from the shed (Pollock and Friebel 2002). In order to completely describe the odour emissions from broiler sheds, it is essential to measure odour emission rates on multiple days and at different times of day throughout the production cycle. Using conventional olfactometry techniques, it would be very expensive and demand large resources to obtain this information. As a consequence, instrumental artificial olfaction systems (sometimes referred to as an electronic nose) with continuous monitoring capability are being developed (Sohn et al. 2008).

The aim of the present study was to measure odour emission rates from modern broiler farms (incorporating modern tunnelventilated sheds, diet, flock-management and litter-management practices) to produce a database of odour emissions that is robust. We anticipate that these data will fill knowledge gaps regarding variability of emission rates throughout the production cycle.
These data could be used to support and improve the modelling of odour dispersion from broiler farms.

\section{Materials and methods}

\section{Farm description}

Odour samples were collected from nine tunnel-ventilated broiler sheds located in south-eastern Queensland (Table 1). On Farm A, odour samples were collected at approximately weekly intervals during two sequential 56-day production cycles. The first batch was raised on fresh bedding, while for the second batch, a partial litter reuse strategy was used whereby all of the soiled litter was retained in the shed (but removed from the brooding section, which occupied approximately half of the shed) and fresh bedding material was used in the brooding section. On Farms B to I, odour samples were collected on the day before the first pickup, when a proportion of the birds was harvested from the shed on approximately Day 35 of the production cycle. Odour emission measurements were undertaken from 13 February 2007 to 4 June 2007 on Farm A, and from 4 April 2008 to 26 May 2008 on Farms $\mathrm{B}$ to I. Weather conditions varied during sampling campaigns at each farm. The research team recorded ambient temperature and humidity so that differences in weather could be taken into consideration when analysing the odour emission rate data.

\section{Sample collection}

On each sampling day, odour samples were collected between 0800 and 1300 hours. This sampling window was chosen to enable the odour samples to be analysed on the same day as collection, to minimise potential olfactometry errors due to sample deterioration with longer periods of storage (i.e. overnight). In addition, collecting odour samples within this time frame enabled odour emission rates to be measured at several ventilation rates on each sampling day (targeting sample collection at $25,50,75$ and $100 \%$ of the daily maximum ventilation rate). This was possible because ventilation rate generally increased with ambient temperature throughout the

Table 1. Specifications of the broiler sheds included in this study

The number of birds is the approximate number of birds that were placed in the shed at the start of a batch. The maximum ventilation rate is an approximate value (based on fan design specifications), likely when all tunnel-ventilation fans are operating. 'Single' refers to all litter being removed from the shed at the end of each batch and being replaced with fresh bedding material throughout. 'Partial reuse' refers to litter from the previous batch being retained in the shed but with fresh bedding material placed in the brooding section of the shed. All sheds used wood shavings for fresh bedding material

\begin{tabular}{lccclc}
\hline Farm & $\begin{array}{c}\text { Shed dimensions } \\
(\mathrm{L} \times \mathrm{W}, \mathrm{m})\end{array}$ & No. of birds & $\begin{array}{c}\text { Maximum ventilation } \\
\text { rate }\left(\mathrm{m}^{3} / \mathrm{s}\right)\end{array}$ & Wall structure & Litter management \\
\hline Farm A & $150 \times 15.5$ & 40450 & 105 & Solid insulated & Single \\
Farm A & $150 \times 15.5$ & 37200 & 105 & Solid insulated & $\begin{array}{c}\text { Partial reuse } \\
\text { Farm B }\end{array}$ \\
$125 \times 13.7$ & 31100 & 95 & Curtains & Partial reuse \\
Farm C & $150 \times 15.5$ & 38800 & 131 & Solid insulated & Partial reuse \\
Farm D & $153 \times 15.0$ & 43350 & 126 & Solid insulated & Single \\
Farm E & $153 \times 15.3$ & 43350 & 142 & Solid insulated & Partial reuse \\
Farm F & $155 \times 15.3$ & 45100 & 115 & Curtains and solid & Partial reuse \\
& & & & Solid insulated walls & Single \\
Farm G & $150 \times 15$ & 44000 & 115 & Solid insulated & Single \\
Farm H & $150 \times 15$ & 43500 & 138 & Curtains & Single \\
Farm I & $120 \times 14.8$ & 35800 & 92 & & \\
\hline
\end{tabular}


morning, as determined by the in-shed environmental control system.

To facilitate the collection of air samples for dilution olfactometry analysis at Farm A, a polyethylene duct $\sim 14 \mathrm{~m}$ long and $1.3 \mathrm{~m}$ in diameter (similar to the duct previously described by Sohn et al. (2008)) was attached to one of the tunnel-ventilation fans, with the other end being open to the atmosphere. This duct was designed to provide a sampling position in accordance with AS 4323.1:1995 (Standards Australia 1995) and prevented interference at the sampling point due to cross-winds. The duct at Farm A was utilised because it was required for a concurrent study in which dust emissions were measured using isokinetic sampling methods (not reported here). While the use of a duct is preferable, it is not essential for odour collection. At Farms B to I, it was not feasible to use a duct, so odour samples were collected directly from the fan face. At these Farms (B-I), the sampling probe was placed within the fan housing to reduce interference and dilution from cross-winds.

Odour samples were collected in customised 120-L drums lined with a specially prepared polyethylene terephthalate (PET, Melinex $^{\circledR}, 15 \mu \mathrm{m}$, DuPont Teijin Films ${ }^{\mathrm{TM}}$, Chester, VA, USA) bag. Bags were filled using negative pressure (lung principle) in an average sampling time of $10 \mathrm{~min}$. Odour samples were transported to the olfactometer and analysed within $8 \mathrm{~h}$ of collection to minimise the possibility of sample deterioration.

\section{Analytical methods}

Olfactometry analysis was performed using an 8-panellist, triangular, forced-choice dynamic olfactometer operated by DEEDI, Toowoomba, which was constructed and operated in compliance with the requirements of the Australian/New Zealand Standard for Dynamic Olfactometry, AS/NZS 4323.3:2001 (Standards Australia/Standards New Zealand 2001). Odour collection methods and the olfactometer have been previously described by Hudson et al. (2006) and Sohn et al. (2008). Odour samples were collected in duplicate and analysed individually to improve confidence in the olfactometry results. On each sampling day, 4-6 pairs of duplicate samples were collected (8-12 sample bags analysed by the olfactometer). The arithmetic mean was calculated for each pair of duplicate samples to produce a single odour-concentration value for each set of sampling conditions.

Ventilation rate was recorded during each odour-sampling event to enable calculation of the odour emission rate. Ventilation rate was determined using fan performance information supplied by the manufacturer, the shed static pressure at the time of sampling, and the number of active fans. Airflow was also routinely measured using a hot-wire anemometer within the shed or at the fan face at each farm as a means of checking that accumulated dust or wear were not reducing fan performance. Ventilation rates determined by all three methods were similar when measured under appropriate conditions, namely when the shed was in tunnel ventilation mode for in-shed measurement, and when winds were absent during fan-face measurements.

Odour emission rate (ou/s) was calculated by multiplying the odour concentration $\left(\mathrm{ou} / \mathrm{m}^{3}\right)$ by the ventilation rate $\left(\mathrm{m}^{3} / \mathrm{s}\right.$, at the time of sample collection, and adjusted for standard conditions,

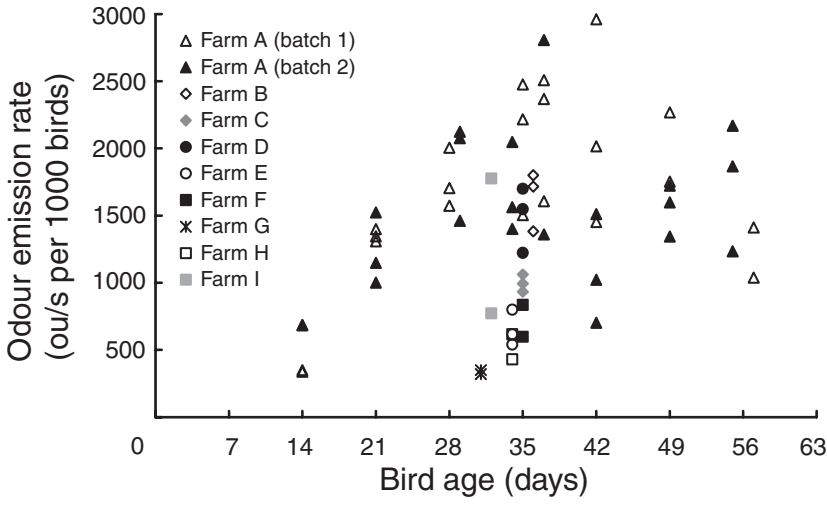

Fig. 1. Odour emission rate per 1000 birds placed (in the shed at the start of the batch).

$0^{\circ} \mathrm{C}$ and $101.3 \mathrm{kPa}$ ) as required by $\mathrm{AS} / \mathrm{NZS}$ 4323.3:2001 (Standards Australia/Standards New Zealand 2001). Odour emission rate values were normalised in terms of odour emission rate per 1000 birds placed in the shed at the start of the batch (ou/s per 1000 birds) and odour emission rate per kilogram of total liveweight (ou/s.kg). These normalisation procedures enabled the measured odour emission rates to be compared with the values reported in the literature and to other sheds of different size. When normalising the odour emission rate in terms of 'per 1000 birds placed at the start of the batch', no adjustment is made for changes in bird numbers throughout the batch due to mortality or pickups.

In addition to dilution olfactometry performed intermittently using grab samples, an artificial olfaction system was used in conjunction with a ventilation activity monitor. This allowed odour emission rates to be measured continuously for the shed at Farm A (Batch 2, partial litter reuse). The use and implementation of the artificial olfaction system was described previously by Sohn et al. (2008). In summary, the artificial olfaction system consists of a customised sensing chamber with 24 metal oxide sensors. Sample air was drawn from within the poultry shed $10 \mathrm{~m}$ upwind from the exhaust fans at a height of $1 \mathrm{~m}$ above the litter. It was calibrated using the olfactometry results derived from assessment of the grab samples.

Litter moisture content was measured using samples of litter collected on each sampling day. The shed floor area was equally divided into 30-45 segments (depending on shed size), with five transects across the width of the shed and 6-9 along its length. Litter samples were collected in each grid segment and individually analysed using gravimetric methods. This provided details regarding the range of moisture contents within the shed and shed average moisture content. It also allowed regions of higher moisture content within the shed to be identified.

Data from Farm A were analysed with linear fixed effects modelling using R Version 2.6.1 (R Development Core Team 2009).

\section{Results}

Measured odour emission rates varied throughout the batch and during each sampling day. Odour emission rates (OER) ranged 


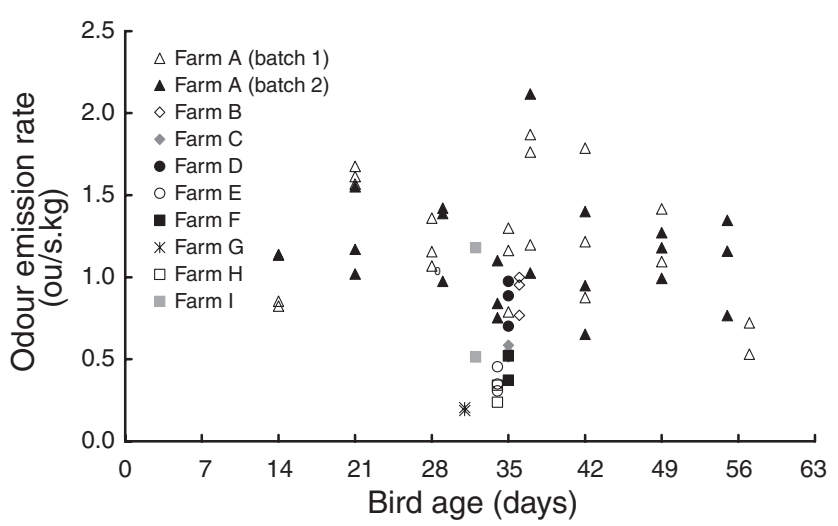

Fig. 2. Odour emission rate per $\mathrm{kg}$ liveweight.

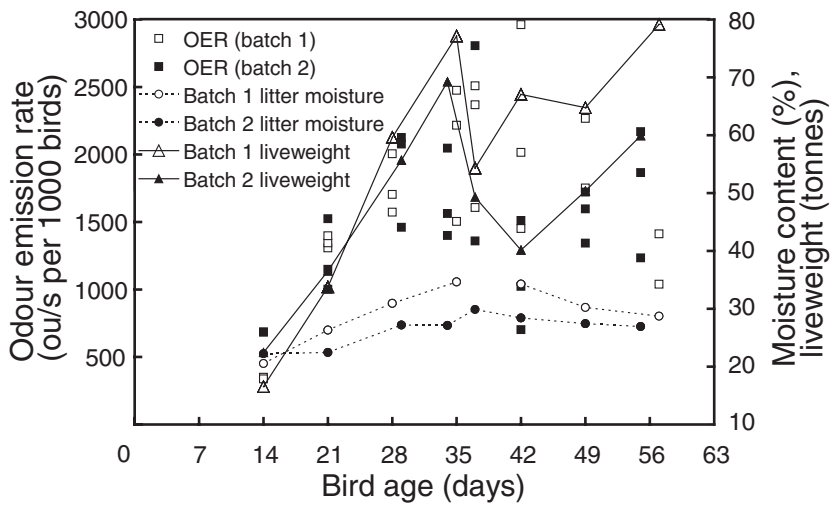

Fig. 3. Odour emission rate (OER, per 1000 birds placed in the shed at the start of the batch), total liveweight and litter moisture content at Farm A. from 330 to $2960 \mathrm{ou} / \mathrm{s}$ per 1000 birds (Fig. 1, normalised using bird numbers placed at the start of the batch) and from 0.19 to $2.12 \mathrm{ou} / \mathrm{s.kg}$ (Fig. 2).

At Farm A, where odour measurements were taken at approximately weekly intervals (Fig. 3), odour emission rate increased strongly with bird total liveweight until the first pickup (Day 36 for Batch 1 and Day 35 for Batch 2). After the first pickup, there was a noticeable decrease in odour emission, corresponding to the reduction in liveweight. Odour emission rate increased once more, as the total liveweight again increased.

Farm A was also used to determine the effect of partially reusing litter on odour emission rates (Fig. 3). Odour emission rate, production and environmental data (including litter moisture content, ambient temperature, weather conditions, ventilation rate, liveweight and pickup schedule) from these two batches were analysed using a linear fixed-effects model. While there was no observed systematic increase in odour emission rate due to the partial litter reuse practices at this farm, no robust conclusions could be made. This was because the analysis was confounded by unavoidable differences between the batches, in particular litter moisture content (Fig. 3) and ambient temperature (and its effects on ventilation rate).

On each sampling day, during the sample collection period from 0800 to 1300 hours, ventilation rate increased in response to increasing ambient temperature. As the ventilation rate increased, odour emission rate also increased. The increase in the ventilation rate explains much of the observed variability in odour emission rates on each sampling day as shown in Figs 1 and 2. It would not be appropriate to average the odour emission rate measurements on each sampling day because each measurement is representative of different conditions, specifically different ventilation rates.

Continuous measurement with the artificial olfaction system and ventilation activity monitoring system demonstrated that

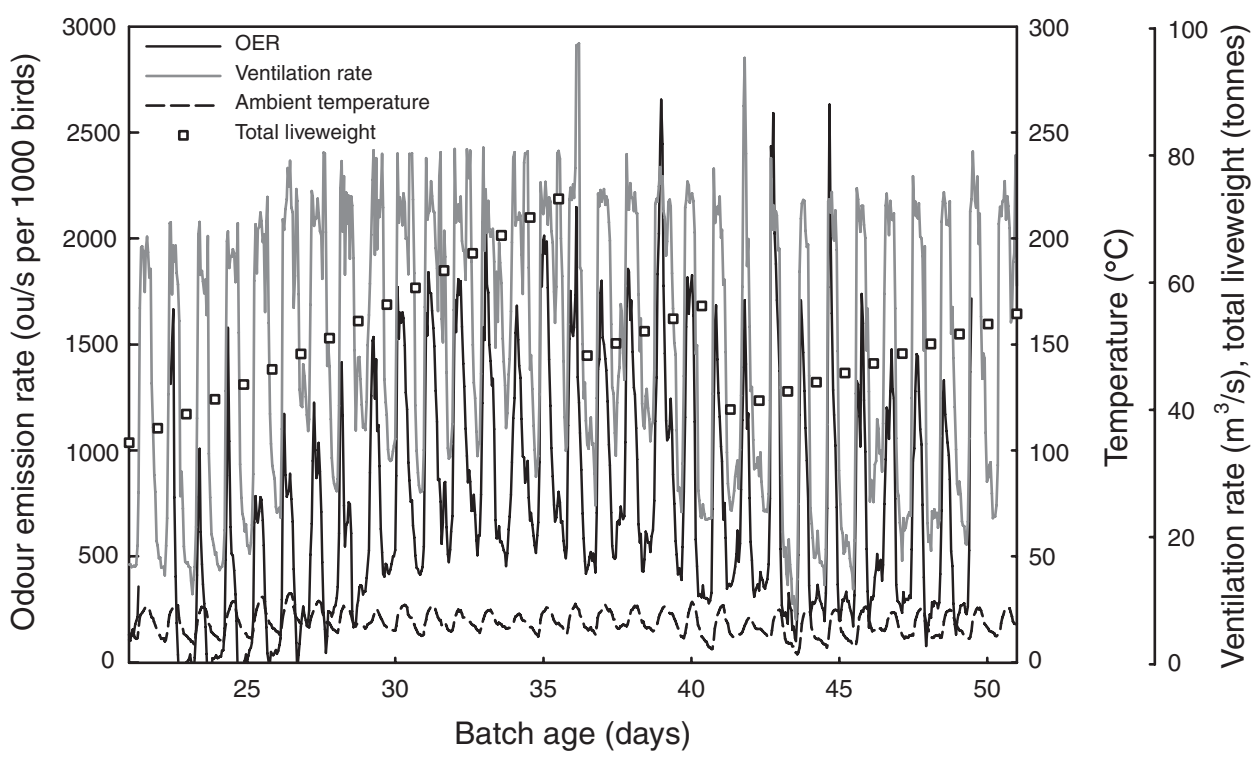

Fig. 4. Continuous record of odour emission rate (OER, per 1000 birds placed in the shed at the start of the batch) from the artificial olfaction system, ventilation rate and ambient temperature at Farm A. 
odour emission rates generally increased with bird liveweight. It was particularly useful in demonstrating how odour emission rates fluctuated diurnally (Fig. 4). Features of the diurnal emission pattern include a short period of peak emission, generally in the afternoon (although the emission rate was observed to peak anytime between 0900 and 1700 hours), and minimum odour emission rates in the night and early morning.

\section{Discussion}

Odour emission rates measured in the present study from tunnelventilated broiler sheds in south-eastern Queensland ranged from 330 to $2960 \mathrm{ou} / \mathrm{s}$ per $1000 \mathrm{birds}$ and from 0.19 to $2.12 \mathrm{ou} / \mathrm{s} . \mathrm{kg}$. These values are generally comparable to values reported in the literature; however, the maximum measured emission rates were higher than those reported in the literature. Comparison of the odour emission rates reported in the literature with those measured in the present study needs to be undertaken cautiously due to differences in building design (e.g. tunnel-ventilated $v$. naturally ventilated or roof-ridge ventilated) and production conditions (especially lower ventilation rates due to much cooler weather).

Odour emission rates measured during this study appeared to vary with farm, ventilation rate, bird age, total liveweight and ambient temperature. Consequently, a range of odour emission rates should be expected from the same shed over the course of a day or batch cycle. While measured emission rates varied widely, primarily due to changes in ventilation rate and bird density, other factors were also likely to affect emission rates. These included litter properties (including moisture content, $\mathrm{pH}$, porosity, manure quantity), temperature, bird activity, weather conditions, air speed and diet. The practice of partially reusing litter as bedding for a subsequent batch did not appear to systematically increase odour emission rate. At this time, we are not able to account for the differences in emission rates measured for the various individual sheds.

The artificial olfaction system proved useful for continuously and affordably monitoring odour emission rates. It allowed continuous monitoring of odour emission rate, which would have been impractical and unaffordable to assess using conventional odour assessment techniques. It revealed the extent and variability of odour emission rates throughout the batch and diurnally. Peak daily odour emission rates were observed to occur generally in the afternoon and minimum emission rates occurred at night and in the morning. These diurnal fluctuations require careful consideration for odour measurement or modelling. Daily odour emission rate peaks and troughs need to be carefully aligned with weather and atmospheric stability conditions when modelling predicted odour impacts.

\section{Acknowledgements}

This research was undertaken through the Australian Poultry Cooperative Research Centre in collaboration with researchers at the University of New South Wales - Gavin Parcsi, Xinguang Wang and Richard Stuetz; Queensland University of Technology - Rob Modini and Zoran Ristovski; and the Department of Primary Industries, Victoria - Ian McCauley and Brett Matthews.

\section{References}

Cai L, Koziel JA, Lo Y-C, Hoff SJ (2006) Characterisation of volatile organic compounds and odorants associated with swine barn particulate matter using solid-phase microextraction and gas chromatography-mass spectrometry-olfactometry. Journal of Chromatography. A 1102, 60-72. doi:10.1016/j.chroma.2005.10.040

Carey JB, Lacey RE, Mukhtar S (2004) A review of literature concerning odors, ammonia, and dust from broiler production facilities: 2 . Flock and house management factors. Journal of Applied Poultry Research 13, 509-513.

EPA Qld Government (2004) Guideline: odour impact assessment from developments. (Environmental Protection Agency: Brisbane, 550 Qld) Available at http://www.derm.qld.gov.au/register/p01344aa.pdf [Verified 21 May 2010]

Hayes ET, Curran TP, Dodd VA (2006) Odour and ammonia emissions from intensive poultry units in Ireland. Bioresource Technology 97, 933-939. doi:10.1016/j.biortech.2005.04.024

Hobbs PJ, Webb J, Mottram TT, Grant B, Misselbrook TM (2004) Emissions of volatile organic compounds originating from UK livestock agriculture. Journal of the Science of Food and Agriculture 84, 1414-1420. doi:10.1002/jsfa. 1810

Hudson N, Ayoko GA (2009) Comparison of emission rate values for odour and odorous chemicals derived from two sampling devices. Atmospheric Environment 43, 3175-3181. doi:10.1016/j.atmosenv. 2009.03.050

Hudson N, Duperouzel D, Melvin S (2006) Assessment of permeable covers for odour reduction in piggery effluent ponds. 1. Laboratory-scale trials. Bioresource Technology 97, 2002-2014. doi:10.1016/j.biortech.2005. 11.002

Hudson N, Ayoko GA, Dunlop M, Duperouzel D, Burrell D, Bell K, Gallagher E, Nicholas P, Heinrich N (2009) Comparison of odour emission rates measured from various sources using two sampling devices. Bioresource Technology 100, 118-124. doi:10.1016/j.biortech.2008.05.043

Jiang J, Sands J (2000) 'Odour and ammonia emission from broiler farms.' RIRDC Pub. 00/2, Project No. UNS-11A. (Rural Industries Research and Development Corporation: Barton, ACT)

Lacey RE, Mukhtar S, Carey JB, Ullman JL (2004) A review of literature concerning odors, ammonia, and dust from broiler production facilities: 1. Odor concentrations and emissions. Journal of Applied Poultry Research 13, 500-508.

McGahan E, Kolominskas C, Bawden K, Ormerod R (2002) Strategies to reduce odour emissions from meat chicken farms. In 'Poultry information exchange (PIX)'. ANA Hotel, Gold Coast, Australia. pp. 27-40. (Poultry Information Exchange Association Inc.: Caboolture, Qld)

O'Neill DH, Phillips VR (1992) A review of the control of odour nuisance from livestock buildings: Part 3, properties of the odorous substances which have been identified in livestock wastes or in the air around them. Journal of Agricultural Engineering Research 53, 23-50. doi:10.1016/ 0021-8634(92)80072-Z

Pollock T, Anderson S (2004) 'Review of modelling, emission measurement and treatment of odour and dust emissions from broiler farms.' Australian Poultry CRC, Project 03-29, ISBN 1-921010-00-2, Armidale, NSW.

Pollock T, Friebel E (2002) Effect of batch age and ambient temperature in broiler shed odour modelling. In 'Enviro2002 conference and exhibition', Melbourne, Australia. (Australian Water Association Inc.: Melbourne, Vic.)

R Development Core Team (2009) R: a Language and environment for statistical computing, version 2.6.1. (R Foundation for Statistical computing: Vienna, Austria)

Robertson AP, Hoxey RP, Demmers TGM, Welch SK, Sneath RW, Stacey KF, Fothergill A, Filmer D, Fisher C (2002) Commercial-scale studies of the effect of broiler-protein intake on aerial pollutant emissions. Biosystems Engineering 82, 217-225. doi:10.1006/bioe.2002.0073 
Schiffman SS, Bennett JL, Raymer JH (2001) Quantification of odors and odorants from swine operations in North Carolina. Agricultural and Forest Meteorology 108, 213-240. doi:10.1016/S0168-1923(01) 00239-8

Sohn JH, Hudson N, Gallagher E, Dunlop M, Zeller L, Atzeni M (2008) Implementation of an electronic nose for continuous odour monitoring in a poultry shed. Sensors and Actuators. B: Chemical 133, 60-69. doi:10.1016/j.snb.2008.01.053

Standards Australia (1995) 'Australian standard: stationary source emissions: selection of sampling positions (AS4323.1-1995).' (Standards Australia International: Sydney)
Standards Australia/Standards New Zealand (2001) 'Stationary source emissions part 3: determination of odour concentration by dynamic olfactometry (AS/NZS 4323.3-2001).' (Standards Australia/Standards New Zealand: Sydney)

Manuscript received 8 December 2009, accepted 12 February 2010 